\title{
MEDIA PEMBELAJARAN POWTOON TERINTEGRASI NILAI-NILAI AGAMA PADA PEMBELAJARAN IPA UNTUK MENGEMBANGKAN KARAKTER
}

\author{
Dwi Gusti Ayu ${ }^{1 *}$, Retno Triwoelandari ${ }^{1}$, Muhammad Fahri ${ }^{1}$ \\ Program Studi Pendidikan Guru Madrasah Ibtidaiyah \\ ${ }^{1}$ Fakultas Agama Islam, Universitas Ibn Khaldun \\ Jalan K.H. Sholeh Iskandar, Bogor, Indonesia \\ *Email: dwigustiayu@gmail.com
}

Website: https://jurnal.uin-antasari.ac.id/index.php/adzka

Received: 5 Juli 2019; Accepted: 11 November 2019; Published: 13 Desember 2019

\begin{abstract}
The purpose of this study is to find out the teaching media of Powtoon integrated with religious values in science learning in developing the discipline character of student. The research method used is a study quasi-experimental with a before-after control group design. This research was conducted in three different schools, with categories of good (A), Medium (B), and Less (C). Data were collected using student discipline character observation sheets and analyzed using t-test by SPSS 20 for windows. The initial observation results in the experiment groups of categories A, B, and C were $20.07,18.62$, and 20.33 consecutively and for the control groups $18.05,18.31,17.91$ respectively. The observation results in the experimental group were $30.86,31.85$, and 31.65 and for the control groups were $25.79,26.92$, and 26.87 respectively. The overall initial and final observations of the experiment group was 31.51 while the control group was 26.53. The results of the 2-railed test sig $0,000<0.05$ indicate that the media Powtoon integrated religious values in science learning can develop the character of student discipline.
\end{abstract}

Key Words: teaching media powtoon; integrated religious values; science learning; character

\begin{abstract}
ABSTRAK
Tujuan penelitian ini untuk mengetahui pengaruh media pembelajaran Powtoon pada pembelajaran IPA yang terintegrasi nilai-nilai agama terhadap karakter disiplin siswa. Metode penelitian yang digunakan yaitu penelitian quasi eksperiment dengan desain before-after control group. Penelitian ini dilaksanakan di tiga sekolah berbeda dengan kategori baik (A), Sedang (B), Kurang (C). Data dikumpulkan menggunakan lembar observasi karakter disiplin siswa dan dianalisis menggunakan uji t dengan bantuan SPSS 20 for windows. Hasil obervasi awal pada kelompok eksperimen sekolah kategori A,B,C masing-masing adalah 20,07; 18,62; 20,35 dan untuk kelompok kontrol masing-masing adalah 18,05; 18,31; 17,91. Hasil observasi akhir pada kelompok eksperimen masing-masing adalah 30,86; 31,85; 31,65 dan untuk kelompok kontrol masing-masing adalah 25,$79 ; 26,92 ; 26,87$. Hasil observasi awal dan akhir secara keseluruhan kelompok eksperimen adalah 31,51; sedangkan kelompok kontrol 26,53. Hasil uji t menunjukan bahwa media pembelajaran Powtoon terintegrasi nilai-nilai agama pada pembelajaran IPA dapat mengembangkan karakter disiplin siswa.
\end{abstract}

Kata Kunci : media pembelajaran powtoon; nilai terintegrasi agama; pembelajaran IPA; karakter 


\section{PENDAHULUAN}

Pendidikan merupakan sarana untuk mewujudkan manusia yang lebih baik lagi. Guru sebagai tenaga pendidik mempunyai peranan penting dalam mengembangkan Sumber Daya Manusia yang lebih baik sesuai dengan tujuan pendidikan nasional yang terdapat dalam UU No. 20 tahun 2003 pasal 3, yaitu: "Berkembangnya potensi peserta didik agar menjadi manusia yang beriman, dan bertaqwa kepada Tuhan Yang Maha Esa, berakhlak mulia, sehat, berilmu, cakap, kreatif, mandiri, dan menjadi warga yang demokratis, serta tanggungjawab". Guru sebagai fasilitator, dan motivator siswa di sekolah diharapkan dapat mewujudkan tujuan pendidikan yang tercatat dalam UU tersebut. Terwujudnya tujuan pendidikan ini dapat dilalui melalui pembelajaran di sekolah. Pembelajaran di sekolah dapat berjalan dengan efektif apabila sarana dan prasarana yang ada mendukung proses belajar siswa. Agar tujuan pendidikan dapat tercapai, maka proses pembelajaran di kelas perlu dilakukan dengan berbagai cara seperti peningkatan sarana dan prasarana sekolah. Salah satunya adalah penggunaan media pembelajaran dalam proses pembelajaran.

Media pembelajaran merupakan sebuah perantara yang digunakan dalam proses pembelajaran, sehingga membuat guru menjadi lebih kreatif dan inovatif dalam menyampaikan materi. Tidak hanya itu, media pembelajaran juga dapat membantu siswa untuk tidak merasa bosan ketika di kelas. Azhar Arsyad (2017:29-30) menjelaskan bahwa manfaat dari media pembelajaran adalah sebagai alat yang dapat memperjelas penyajian pesan dan informasi sehingga memperlancar dan meningkatkan proses pembelajaran, hasil belajar, maupun motivasi siswa dalam berinteraksi pada pembelajaran. Media sangat berguna dalam proses pembelajaran (Nida, 2017, 2019). Kegunaan media pembelajaran Powtoon diantaranya dapat memperjelas penyajian materi melalui animasi-animasi yang terdapat dalam Powtoon yang disajikan dalam bentuk film atau video yang berhubungan dengan materi pembelajaran (Maesyaroh, 2018:1920). Pengertian Powtoon itu sendiri merupakan sebuah perangkat lunak berbasis animasi, yang dapat dijadikan sebuah media pembelajaran dalam dunia pendidikan (Mersand, 2014). Berdasarkan penjelasan tersebut mengenai manfaat media dalam proses pembelajaran maupun fungsi Powtoon, maka sebelum guru membuat media pembelajaran, akan lebih baik guru melakukan analisis kebutuhan siswa, agar tujuan pendidikan yang diharapkan terwujud lewat bantuan media pembelajaran tersebut. Selain mengenai kebutuhan siswa, guru pun perlu melakukan analisis atas masalah-masalah yang terjadi pada dunia pendidikan saat ini secara umum, maupun masalah yang terjadi dalam proses pembelajaran secara khusus (Kurdi, 2018: 231), yang diharapkan dapat membuat perubahan dalam proses pembelajaran.

Permasalahan paling utama dalam dunia pendidikan di Indonesia saat ini adalah berkurangnya nilai-nilai dalam karakter peserta didik (Kurdi, 2018: 125). banyak peserta didik yang tidak disiplin dan melakukan pelanggaran di sekolah, selain itu juga ditemukan peserta didik yang melakukan hal-hal di luar batas wajar. Seperti yang diberitakan oleh Walid (2014) mengenai kasus kekerasan yang dilakukan oleh anak Sekolah Dasar (SD) yang menghujani tendangan dan pukulan kepada temannya di pojokan kelas, ia menjelaskan tidak adanya pembelaan terhadap korban, siswa yang lainnya sibuk dengan kegiatannya masing-masing, kasus ini sangat memprihatinkan bahwa sangat kurangnya karakter siswa di sekolah (Tribunnews Online, 13 Oktober 2014). Kepolisian Resor Kota Bogor mencatat angka kasus tawuran di kota tersebut mengalami peningkatan. Berdasarkan data yang ada, pada tahun 2014 terjadi 63 kasus tawuran dan menyebabkan satu orang meninggal dunia, pada tahun 2015 mencapai 76 kasus dan dua meninggal. Kasus terakhir pada tahun 2018 bulan Feburari yang menewaskan satu orang (Berita dalam Metrotvnews, 10 Februari 2018). Kasus-kasus ini merupakan hanya beberapa dari sekian banyak kasus-kasus yang terjadi di kalangan pelajar di Indonesia yang mengindikasikan sangat kurangnya karakter siswa. Padahal dalam kurikulum 2013 sudah dirancang dengan muatan penguatan pendidikan karakter di dalam setiap pembelajaran. 
Kurikulum 2013 telah mempermudah guru untuk menumbuhkan pendidikan karakter di sekolah. Kementerian pendidikan nasional (Kemendiknas 2011, 5) menyebutkan pembangunan karakter merupakan perwujudan amanat Pancasila dan Pembukaan UUD 1945. Pembangunan karakter bangsa pada tahun 2010-2025 menyebutkan bahwa pendidikan karakter merupakan pondasi utama untuk mewujudkan visi pembangunan nasional yaitu masyarakat berkahlak mulia, bermoral, beretika, berbudaya, dan berabad, berdasarkan falsafah Pancasila. Terdapat 18 nilai karakter yang dicanamkan oleh Kemendiknas, yang dapat dikembangkan pada sekolah-sekolah, nilai-nilai karakter ini bersumber pda, pancasila, budaya, dan tujuan pendidikan nasional (Kemendiknas 2010, 9-10).

Berdasarkan hal tersebut maka perlunya pengembangan karakter siswa-siswi di Indonesia. Maka melalui media pembelajaran diharapkan dapat mengembangkan karakter siswa terlebih karakter disiplin siswa. Agar karakter siswa semakin kuat dan kokoh maka perlunya sebuah inovasi baru mengenai pembelajaran yaitu dengan media pembelajaran yang mengintegrasikan antara pembelajaran umum khususnya pembelajaran IPA dengan nilai-nilai Islam, agar pemahaman siswa mengenai nilai-nilai agamanya pun tidak kurang dan paham akan nilai-nilai agama. Dalam seminar pendidikan di yang selenggaran di kota Sigli, Mendikbud Muhajir Effendy (2018) yang diberikan oleh Nihayati, Muhajir Effendy menjelaskan bahwa perlunya nilai-nilai agama dengan baik guna membangun karakter siswa di sekolah (Berita dalam Aceh Tribunnews, 06 Mei 2019). Oleh sebab itu, pengintegrasian antara pembelajaran dengan nilai-nilai agama sangat diperlukan guna mengembangkan karakter siswa. Karakter siswa yang perlu dikembangkan dengan melihat kasus-kasus di atas berupa karakter disiplin siswa. Disiplin merupakan sebuah tindakan yang menunjukan perilaku tertib dan patuh, pada berbagai ketentuan dan peraturan yang berlaku (Yaumi, 2014:92-95). Sedangkan integrasi yang dimaksud merupakan integrasi dengan pembelajaran IPA, di mana cara yang digunakan berupa Islamisasi Sains. Handrianto (2010:174) konsep pembelajaran IPA dengan nilai-nilai Islam yaitu dengan cara Islamisasi sains, yang di mana mengintegrasikan antara ilmu pengetahuan Barat dengan ilmu-ilmu keislaman. Untuk mengembankan hal tersebut maka perlunya sebuah alat bantu pembelajaran berupa media pembelajaran.

Media pembelajaran Powtoon merupakan media pembelajaran yang inovatif dan

kreatif. Powtoon merupakan sebuah aplikasi yang dapat dijadikan media pembelajaran, Powtoon terdapat banyak animasi-animasi yang menarik (Половін, 2018; Buchori, 2018: 221) dan template-template yang membuat siswa tidak bosan ketika pembelajaran. Tidak hanya itu media pembelajaran Powtoon $n$ ini juga berguna untuk mewujudkan manusia yang lebih baik lagi dengan berpendidikan, dan mengintegrasikan nilai-nilai agama. Hasil penelitian terdahulu, menyatakan bahwa dengan media pembelajaran Powtoon dapat meningkatkan hasil belajar siswa (Chandler, 2015; Julianingrum, Muchsini \& Adi, 2015; Adkhar, 2015; Fimbriani, 2016; Fajar, Riyana, Hanoum 2017, 101-114; Suhendra, Enawaty, \& Melati, 2018; Nurdiansyah, 2018). Selain itu, media ini juga dapat meningkatkan motivasi siswa dalam belajar (Suhendra, Enawaty, Melati 2018, 7; Puspitarini, 2018; Liesdiani, 2016), dan juga mampu meningkatkan kemampuan berfikir kritis siswa (Purwanti \& Suryani, 2018). Oleh sebab itu, perlu diadakan penelitian yang bertujuan untuk mengetahui pengaruh media pembelajaran Powtoon pada pembelajaran IPA terintegrasi nilai-nilai agama terhadap pengembangan karakter disiplin siswa yang dikategorikan menjadi baik, sedang, dan kurang.

\section{METODE PENELITIAN}

Metode kuantitatif digunakan dalam penelitian ini dengan desain quasi eksperiment (Campbell \& Riecken, 1968) before-after control group desain dengan membandingkan antara hasil observasi awal dan observasi akhir pada kelas eksperimen dan kelas kontrol. Kelas eksperimen menggunakan media pembelajaran Powtoon terintegrasi nilai-nilai agama pada 
pembelajaran IPA dan kelas kontrol tidak menggunakan media tersebut. Variabel yang diukur yaitu karakter disiplin siswa pada kedua kelas tersebut.

Penelitian ini dilakukan di tiga sekolah yang berada di Kecamatan Cibungbulang, dengan alamat Jalan Raya Cibungbulang KM 18 Desa Cimanggu II Kecamatan Cibungbulang Kabupaten Bogor. Waktu pelaksanaan penelitian pada 02 Januari 2019 hingga 31 Januari 2019. Populasi yang ada pada penelitian ini yaitu Sekolah Dasar Negeri yang berada di Kecamatan Cibungbulang dengan teknik sampling acak statifikasi. Pada penelitian ini, sekolah dibagi menjadi tiga strata yaitu sekolah baik, sedang, dan kurang yang akan dipaparkan pada tabel berikut :

Tabel. 1 Jumlah Sampel Penelitian

\begin{tabular}{|c|c|c|c|c|}
\hline Kelas/ Kategori & Sekolah A & Sekolah B & Sekolah C & Jumlah \\
\hline Eksperimen & 42 siswa & 39 siswa & 23 siswa & 104 \\
\hline Kontrol & 42 siswa & 39 siswa & 23 siswa & 104 \\
\hline Jumlah & 84 siswa & 78 siswa & 46 siswa & $\mathbf{2 0 8}$ \\
\hline
\end{tabular}

Pada penelitian ini, digunakan teknik pengumpulan data dengan mengukur karakter disiplin siswa, penilian observasi karakter disiplin siswa ini menggunakan skala Likert dengan ketentuan penilaian $4=$ sangat terlihat, $3=$ terlihat, $2=$ mulai terlihat, $1=$ tidak terlihat Lembar observasi ini berupa indikator pencapaian karakter disiplin yang berjumlah 12 indikator pencapaian.

Tabel 2. Lembar Observasi karakter Disiplin

\begin{tabular}{|l|l|}
\hline Variabel & \multicolumn{1}{|c|}{ Indikator Pencapaian } \\
\hline \multirow{4}{*}{ Disiplin } & 1. Datang sekolah tepat waktu \\
\cline { 2 - 3 } & 2. Masuk kelas tepat waktu \\
\cline { 2 - 3 } & 3. Melaksanakan tugas tepat pada waktunya \\
\cline { 2 - 3 } & 4. Menggunakan seragam sekolah sesuai dengan jadwal \\
\cline { 2 - 3 } & 5. Mematuhi aturan yang terdapat dalam sekolah maupun kelas \\
\cline { 2 - 3 } & 6. Merapihkan alat-alat praktikum yang telah digunakan \\
\cline { 2 - 3 } & 7. Menjaga sikap ketika dengan guru maupun teman-temannya \\
\cline { 2 - 3 } & 8. Duduk pada tempat yang telah ditetapkan \\
\cline { 2 - 3 } & 9. Menjalankan ibadah tepat waktu \\
\cline { 2 - 3 } & 10. Menerapkan penggunaan sumber energi panas dalam kehidupan sehari-hari \\
\cline { 2 - 3 } & 11. Menerapkan konsep perubahan kalor dalam kehidupan sehari-hari \\
\hline
\end{tabular}

Teknik analisis data yang digunakan dalam penelitian ini melihat karakter disiplin siswa dengan menggunakan media pembelajaran Powtoon terintegrasi nilai-nilai agama, data dianalisis dengan menggunakan aplikasi SPSS 20 for windows, data yang dianalisis tersebut merupakan data hasil pengamatan karakter disiplin kelas eksperimen dan kelas kontrol. Data dianalisis dengan menggunakan uji t yaitu paired sampel t-test untuk menguji rata-rata data berpasangan yaitu observasi awal dan observasi akhir. Sedangkan untuk perbandingan rata-rata data tidak berpasangan atau observasi akhir antara kelas eksperimen dan kelas kontrol menggunakan uji-t, independent sampel t-test.

\section{HASIL PENELITIAN DAN PEMBAHASAN}

Berdasarkan hasil penelitian yang telah dilakukan di Sekolah A, Sekolah B, dan Ssekolah C mengenai media pembelajaran Powtoon terintegrasi nilai-nilai agama pada pembelajaran IPA untuk mengembangkan karakter disiplin, menunjukan hasil sebagai berikut: 
Tabel 3. Hasil Rata-rata Oberservasi Awal dan Observasi Akhir

\begin{tabular}{|c|c|c|c|}
\hline \multirow{2}{*}{ Sekolah } & \multirow{2}{*}{ Kelas } & \multicolumn{2}{|c|}{ Penilaian } \\
\cline { 3 - 4 } & & $\begin{array}{c}\text { Observasi } \\
\text { Awal }\end{array}$ & $\begin{array}{c}\text { Observasi } \\
\text { Akhir }\end{array}$ \\
\hline \multirow{2}{*}{ Sekolah A } & Eksperimen & 20,07 & 31,04 \\
\cline { 2 - 4 } & Kontrol & 18,05 & 25,79 \\
\hline \multirow{2}{*}{ Sekolah B } & Eksperimen & 18,62 & 31,85 \\
\cline { 2 - 4 } & Kontrol & 18,31 & 26,92 \\
\hline \multirow{2}{*}{ Sekolah C } & Eksperimen & 20,35 & 31,65 \\
\cline { 2 - 4 } & Kontrol & 17,91 & 26,87 \\
\hline \multirow{2}{*}{ Rata-rata } & Eksperimen & 19,68 & 31,51 \\
\cline { 2 - 4 } & Kontrol & 18,09 & 26,53 \\
\hline
\end{tabular}

Berdasarkan tabel 3, diperoleh hasil penilaian pada setiap sekolah mengalami peningkatan. Hasil observasi akhir mengalami peningkatan terhadap hasil observasi awal . Pada sekolah A kelas eksperimen mengalami peningkatan sebesar 10,97 sedangkan pada kelas kontrol mengalami peningkatan sebesar 7,74. Sekolah B kelas eksperimen mengalami peningkatan sebesar 13,23 sedangkan pada kelas kontrol mengalami peningkatan sebesar 8,62. Sekolah C kelas eksperimen mengalami peningkatan sebesar 11,30; sedangkan kelas kontrol mengalami peningkatan sebesar 8,96 .

Setiap kelas mengalami peningkatan pada hasil observasi akhir, namun peningkatan lebih besar terjadi pada kelas eksperimen yang di mana pada kelas eksperimen menggunakan media pembelajaran Powtoon terintegrasi nilai-nilai agama pada pembelajaran IPA yang digunakan untuk mengembangkan karakter disiplin siswa. Sedangkan kelas kontrol tidak menggunakann media pembelajaran Powtoon terintegrasi nilai-nilai agama untuk mengembangkan karakter disiplin siswa. Adapun hasil nyata peningkatan pengembangan karakter disiplin siswa dengan menggunakan media pembelajaran Powtoon terintegrasi nilainilai agama pada pembelajaran IPA dapat dilihat berdasarkan hasil perhitungan uji t dengan menggunakan SPSS 20 for windows. Sebelum menganalisis data uji t maka dilakukan uji normalitas dan uji homogenitas terlebih dahulu, untuk mengetahui data tersebut berdistribusi normal atau tidak, bersifat homogen atau tidak. Berdasarkan hasil uji normalitas dan homogenitas mendapatkan hasil data tersebut berdistribusi normal dan homogen.

Tabel 4. Paired Sample T-Test Karakter Disiplin Kelas Eksperimen

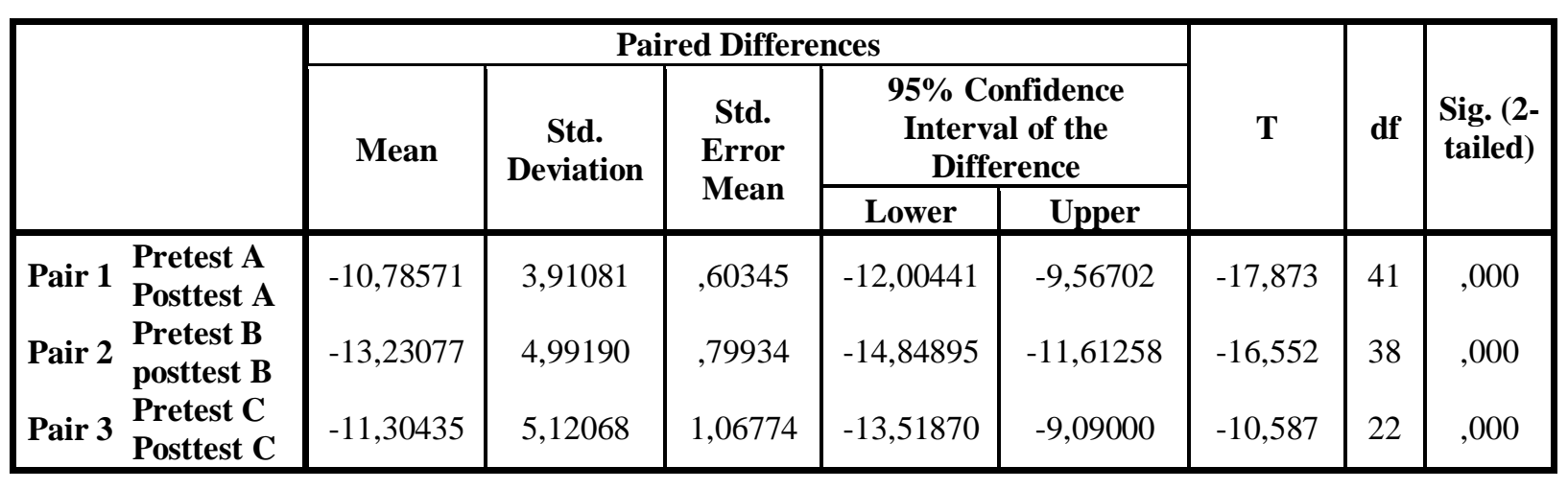


Tabel 5. Paired Sampel T-Test Karakter Disiplin Kelas Kontrol

\begin{tabular}{|c|c|c|c|c|c|c|c|c|c|}
\hline & \multicolumn{5}{|c|}{ Paired Differences } & \multirow{3}{*}{$\mathbf{T}$} & \multirow{3}{*}{ df } & \multirow{3}{*}{$\begin{array}{l}\text { Sig. (2- } \\
\text { tailed) }\end{array}$} \\
\hline & & \multirow{2}{*}{ Mean } & \multirow{2}{*}{$\begin{array}{c}\text { Std. } \\
\text { Deviation }\end{array}$} & \multirow{2}{*}{$\begin{array}{c}\text { Std. } \\
\text { Error } \\
\text { Mean }\end{array}$} & \multicolumn{2}{|c|}{$\begin{array}{c}95 \% \text { Confidence Interval } \\
\text { of the Difference }\end{array}$} & & & \\
\hline & & & & & Lower & Upper & & & \\
\hline Pair 1 & $\begin{array}{l}\text { Pretest A } \\
\text { Posttest A }\end{array}$ & $-7,73810$ & 3,58900 & ,55380 & $-8,85651$ & $-6,61968$ & $-13,973$ & 41 & ,000 \\
\hline Pair 2 & $\begin{array}{l}\text { Pretest B } \\
\text { posttest B }\end{array}$ & $-8,61538$ & 3,28165 &, 52548 & $-9,67917$ & $-7,55160$ & $-16,395$ & 38 & ,000 \\
\hline Pair 3 & $\begin{array}{l}\text { Pretest C } \\
\text { Posttest C }\end{array}$ & $-8,95652$ & 4,56746 & ,95238 & $-10,93164$ & $-6,98141$ & $-9,404$ & 22 & ,000 \\
\hline
\end{tabular}

Berdasarkan tabel 4. pada kelas eksperimen dan 5. Pada kelas kontrol menyatakan bahwa adanya perbedaan antara hasil observasi awal dan hasil observasi akhir pada masingmasing kelas dengan melihat hasil akhir yaitu sig 2-tailed yang menyatakan 0,000. Angka 0,000 $<0,05$ hal ini menunjukan bahwa adanya peningkatan yang signifikan antara masing-masing kelas. Berdasarkan hasil paired sampel t-test kelas eksperimen dan kelas kontrol secara statistika menyatakan bahwa terdapat perbedaan antara hasil observasi awal dan hasil observasi akhir, namun peningkatan paling tingga terdapat pada kelas eksperimen. Hal ini menunjukan bahwa dengan menggunakan media pembelajaran Powtoon terintegrasi nilai-nilai agama pada pembelajaran IPA dapat mengembangkan karakter disiplin pada siswa. Berdasarkan hasil tersebut maka analisis selanjutnya yaitu menggunakan independent sampel t-test untuk menganalisis hasil observasi akhir pada kelas eksperimen dan kelas kontrol. Berikut hasil independent sampel t-test:

Tabel 6. Independent Sampel T-Test Karakter Disiplin Kelas Eksperimen dan Kelas Kontrol

\begin{tabular}{|c|c|c|c|c|c|c|c|c|c|c|}
\hline & \multicolumn{2}{|c|}{$\begin{array}{c}\text { Levene's } \\
\text { Test for } \\
\text { Equality of } \\
\text { Variances }\end{array}$} & \multicolumn{7}{|c|}{ t-test for Equality of Means } \\
\hline & & \multirow[t]{2}{*}{$\mathbf{F}$} & \multirow[t]{2}{*}{ Sig. } & \multirow[t]{2}{*}{ t } & \multirow[t]{2}{*}{ Df } & \multirow{2}{*}{$\begin{array}{l}\text { Sig. } \\
\text { (2- } \\
\text { tailed) }\end{array}$} & \multirow[t]{2}{*}{ Mean } & \multirow[t]{2}{*}{$\begin{array}{l}\text { Std. } \\
\text { Error }\end{array}$} & \multicolumn{2}{|c|}{$\begin{array}{l}\text { 95\% Confidence } \\
\text { Interval of the } \\
\text { Difference }\end{array}$} \\
\hline & & & & & & & & & Lower & Upper \\
\hline \multirow{2}{*}{$\begin{array}{l}\text { karakter } \\
\text { disiplin }\end{array}$} & $\begin{array}{l}\text { Equal } \\
\text { variances } \\
\text { assumed }\end{array}$ & 1,710 & 192 & 9,503 & 206 & ,000 & 4,95192 & 52110, & 3,92455 & 5,97930 \\
\hline & $\begin{array}{l}\text { Equal } \\
\text { variances } \\
\text { not } \\
\text { assumed }\end{array}$ & & & 9,503 & 201,032 &, 000 & 4,95192 & ,52110 & 3,92440 & 5,97945 \\
\hline
\end{tabular}

Berdasarkan hasil tabel 6, mengenai independent sampel $t$-test diperoleh hasil perbedaan rata-rata antara kelas eksperimen dan kelas kontrol sebesar 4,95192. Hasil akhir pada analisis ini melihat pada sig 2-tailed sebesar 0,000. Hal ini menunjukan bahwa bahwa sig 2-tailed , 0,05. Dasar pengambilan keputusan yaitu jika nilai sig 2-tailed $<0,05$ maka Ha diterima terdapat perbedaan yang signifikan, sebaliknya jika nilai sig 2-tailed $>0,05$ maka Ho diterima dan tidak adanya perbedaan yang signifikan. Hasil pada tabel di atas menyatakan nilai sig 2-tailed $<0,05$ maka Ha diterima dan tolak Ho. Maka adanya perbedaan yang signifikan antara hasil observasi akhir pada kelas eksperimen yang menggunakan media pembalajaran Powtoon terintegrasi nilai-nilai agama pada pembelajaran IPA untuk mengembangkan karakter disiplin siswa, 
dengan hasil observasi akhir kelas kontrol yang tidak menggunakan media pembelajaran Powtoon terintegrasi nilai-nilai agama pada pembelajaran IPA.

Hasil penelitian di atas menyatakan adanya peningkatan terdapat karakter disiplin siswa dengan menggunakan media pembelajaran Powtoon terintegrasi nilai-nilai agama pada pembelajaran IPA. Karakter disiplin siswa ini meningkat dan diterapkan siswa dalam kehidupan sehari-hari seperti disiplin dalam beribadah, disiplin ke sekolah maupun peraturan yang ada pada sekolah. Dengan adanya integrasi nilai-nilai agama ini pun membuat siswa lebih paham mengenai materi mengenai nilai-nilai agama yang ada kaitannya dengan ilmu pengetahuan terutama dalam pembelajaran IPA. Penggunaan media pembelajaran Powtoon terintegrasi nilai-nilai agama pada pembelajaran IPA untuk mengembangkan karakter disiplin pun dapat digunakan di sekolah berkategori baik, sedang, maupun kurang. Hasil penelitian untuk menguji pengunaan media ini pun menyatakan bahwa setiap sekolah mengalami peningkatan walaupun peningkatan paling besar berada pada sekolah berkategori sedang. Namun sekolah baik dan kurang pun tetap mengalami peningkatan yang signifikan terhadap pengembangan karakter disiplin siswa.

Hasil penelitian mengenai media pembelajaran Powtoon ini pun sejalan dengan hasil penelitian yang telah dilakukan bahwa media pembelajaran Powtoon dapat meningkatkan hasil belajar dan minat siswa (Ariyanto, Kantun, dan Sukidin 2018, 126). Dengan media pembelajaran Powtoon dapat meningkatkan hasil belajar dan minat siswa, namun dalam penelitian ini peningkatan yang terjadi mengenai karakter disiplin siswa. Hasil penelitian lain pun menyebutkan bahwa dengan menggunakan media pembelajaran Powtoon dapat meningkatkan motivasi dalam belajar siswa ketika menggunakan media pembelajaran Powtoon (Yulia, Ervinalisa 2017, 23). Sedangkan hasil penelitian yang berkenaan dengan penggunaan media pembelajaran terintegrasi nilai-nilai Islam untuk mengembangkan karakter didapati hasil, bahwa dengan menggunakan media pembelajaran terintegrasi nilai-nilai Islam pada pembelajaran IPA dapat mengembangkan karakter siswa (Muslimah, Triwoelandari, Sutisna 2018, 244).

\section{PENUTUP}

Hasil penelitian pada media pembelajaran Powtoon terintegrasi nilai-nilai agama pada pembelajaran IPA menyatakan bahwa terdapat peningkatan karakter disiplin siswa dilihat dari hasil observasi akhir mendapatkan rata-rata secara keseluruhan sebesar 31,5139 untuk kelas eksperimen, dan untuk kelas kontrol rata-rata secara keseluruhan sebesar 26,5267. Hasil ratarata ini menyatakan bahwa dengan menggunakan media pembelajaran Powtoon terintegrasi nilai-nilai agama pada pembelajaran IPA dapat mengembangkan karakter disiplin siswa. Media pembelajaran Powtoon terintegrasi nilai-nilai agama pada pembelajaran IPA ini pun dapat digunakan diberbagai sekolah berkategori baik, sedang, maupun kurang. Hasil analisis data menggunakan uji independent sampel t-test mendapatkan nilai sig 2-tailed sebesar 0,000 yang berarti < 0,05 maka Ha diterima dan tolak Ho. Nilai sig 2-tailed 0,000 menyatakan bahwa adanya perbedaan yang signifikan antara hasil observasi akhir kelas eksperimen dengan hasil observasi akhir kelas kontrol. Perbedaan tersebut karena pada kelas eksperimen menggunakan media pembelajaran Powtoon terintegrasi nilai-nilai agama pada pembelajaran IPA, sedangkan kelas kontrol tidak menggunakan media pembelajaran Powtoon.

Saran bagi lembaga pendidikan agar dapat mendorong para guru agar menfaatkan teknologi untuk dijadikan media pembelajaran dan membuat media pembelajaran dengan mengintegrasikan nilai-nilai agama dalam kegiatan belajar disekolah dalam mengembangkan karakter. Saran bagi pengembang selanjutnya agar dapat mengembangkan produk media pembelajaran Powtoon ini diberbagai mata pelajaran, di kelas yang berbeda dan mengembangkan karakter-karakter lainnya dengan mengintegrasikan nilai-nilai agama pada setiap mata pelajaran di sekolah. 


\section{DAFTAR PUSTAKA}

Adkhar, B. I. (2015). Pengembangan Media Video Animasi Pembelajaran Berbasis Powtoon pada Kelas 2 Mata Pelajaran Ilmu Pengetahuan Alam Disd Labschool Unnes (Doctoral dissertation, Universitas Negeri Semarang).

Ariyanto, R., Kantum, S., Sukidin. (2018). "Pengunaan Media Powtoon untuk Meningkatkan Minat dan Hasil Belajar Siswa pada Kompetensi Dasar Mendeskripsikan Pelaku-pelaku Ekonomi dalam Sistem Perekonomian Indonesia (Studi Kasus pada Siswa Kelas VIIID) SMP Nurul Islam Jember Semester Genap Tahun Pelajaran 2017-2018)”. Jurnal Pendidikan Ekonomi. 12(1): 122-127.

Arsyad, A. (2017). Media Pembelajaran. Jakarta: PT RajaGrafindo Persada.

Buchori, A., \& Cintang, N. (2018). The Influence of Powtoon-Assisted Group to Group Exchange and Powtoon-Assisted Talking Chips Learning Models in Primary Schools. International Journal of Evaluation and Research in Education, 7(3), 221-228.

Campbell, D. T., \& Riecken, H. W. (1968). Quasi-experimental design. International encyclopedia of the social sciences, 5, 259-263.

Chandler, P. (2015). PowToon. The School Librarian, 63(2), 84.

Fajar S, Riayana C, Hanoum. (2017). "Pengaruh Pengunaan Media Powtoon Terhadap Hasil Belajar Siswa pada Mata Pelajaran Ilmu Pengetahuan Sosial Terpadu". Jurnal EDUTCEHNOLOGIA. 3(2): 101-114. https://ejournal.upi.edu

Fimbriani, S. C. (2016). The Use Of Teaching Media Powtoon To Improve Eleventh Grade Of Language Class Students'writing Ability at SMA Negeri 1 Malang (Doctoral Dissertation, University of Muhammadiyah Malang).

Handrianto, Budi. (2010). Islamisasi Sanis. Jakarta: Pustaka Al-Kausar.

Julianingrum, I. R., Muchsini, B., \& Adi, W. (2015). Model Pembelajaran Artikulasi dengan Media Animasi Powtoon untuk Meningkatkan Prestasi Belajar Mata Pelajaran Akuntansi Keuangan. In Prosiding Seminar Nasional Pendidikan Akuntansi dan Keuangan.

Kementerian Pendidikan Nasional. (2010). Pengembangan Pendidikan Budaya dan Karakter Bangsa. Jakarta: Badan Penelitian dan Pengembangan.

Kementerian Pendidikan Nasional. (2011). Panduan Pelaksanaan Pendidikan Karakter. Jakarta: Badan Penelitian dan Pengembangan.

Kurdi, M. S. (2018). Evaluasi Implementasi Desain Pendidikan Karakter Berbasis Pendekatan Humanistik. Elementary: Jurnal Ilmiah Pendidikan Dasar, 4(2), 125-138.

Kurdi, M. S. (2018). Madrasah Ibtidaiyah dalam Pandangan Dunia: Isu-Isu Kontemporer dan Tren dalam Pendidikan. Al Ibtida: Jurnal Pendidikan Guru MI, 5(2), 231-248.

Liesdiani, D., Syaodih, E., \& Mariam, P. (2016). Pengembangan Multimedia Pembelajaran Berbasis Audio Visual Powtoon untuk Meningkatkan Motivasi Belajar. Jurnal Pendidikan dan Pembelajaran Ekonomi Akuntansi, 2(2).

Maesyaroh, I. A. (2018). Pengembangan Media Pembelajaran Fisika Berbasis Powtoon pada Materi Dinamika untuk SMA Kelas X. Skripsi Pendidikan Fisika UIN Raden Intan Lampung. http://respository.radenintan.ac.id

Mersand, S. (2014). Product Review Powtoon. https://www.techlearning.com

Muslimah.F, Triwoelandari.R, Sutisna. (2018). "Pengaruh Media Pembelajaran IPA Terintegrasi Nilai-nilai Islam dalam Mengembangkan Karakter Religius Siswa Kelas 5 Sekolah Dasar". Proceeding The 1st AcoMT UIN Sunan Kalijaga Yogyakarta. 244-252. ISBN: 978-602-50472-1-3.

Nihayati, N. (2019, 06 Mei). Mendikbud Singgung Minimnya Pendidikan Agama di Sekolah. Serambinews.com http://aceh.tribunnews.com

Mufidah, N. (2017). The Impact of Video-Making Activities on Student's Grammar 
Mastery. Tarbiyah: Jurnal Ilmiah Kependidikan, 6(1).

Mufidah, N. (2019). The Development of Pre-Service Teachers' Teaching Performance in the Teaching Practice Program at English Department of State Islamic University of Antasari Banjarmasin. Dinamika Ilmu, 19(1), 97-114.

Noor, M.M. (2018, 10 Febuari). Kasus Tawuran di Kota Bogor. Metro Tv News. http://m.metrotvnews.com

Nurdiansyah, E., El Faisal, E., \& Sulkipani, S. (2018, November). Utilization Of Powtoon To Improve Student Learning Outcomes at Citizenship Education Course. In Sriwijaya University Learning and Education International Conference (Vol. 3, No. 1, pp. 627630).

Половін, С. М. (2018). PowToon is an easy way to make your classes more interesting.

Purwanti, K. Y., \& Suryani, E. (2018). Pengaruh Discovery Learning dengan Pendekatan Scientific Berbantuan Powtoon terhadap Motivasi dan Kemampuan Berpikir Kritis. JANACITTA, 1(01).

Puspitarini, Y. D., Akhyar, M., \& Djono, D. (2018, July). Developing Powtoon-Based Video Learning Media for Five Grade Students of Elementary School. In International Conference of Communication Science Research (ICCSR 2018). Atlantis Press.

Suhendra, I., Enawaty, E., Melati, H.A. (2018). "Pengaruh Pengunaan Media Audiovisual Powtoon Terhadap Motivasi dan Hasil Belajar Siswa Materi Unsur Senyawa Campuran”. Jurnal Pendidikan dan Pembelajaran. 7(3): 1-8. http://jurnal.untan.ac.id

Walid, A. (2014, 13 Oktober). Rendahnya Pendidikan Karakter Penyebab Kekerasan Murid SD di Bukittinggi. Tribunners. http://m.tribunnews.com

Yaumi, M. (2014). Pendidikan Karakter: Landasan Pilar dan Implementasi. Jakarta: Prenandamedia Group.

Yulia.D., Ervinalisa.N. (2017). "Pengaruh Media Pembelajaran Powtoon pada Mata Pelajaran Sejarah Indonesia dalam Menumbuhkan Movitasi Belajar Siswa IIS Kelas X di SMA Negeri 17 Batam 2017-2018”. Jurnal Program Studi Pendidikan Sejarah. 2(1): 15-24. 
Dwi Gusti Ayu, dkk 